\title{
BUDI DAYA DAN PENGELOLAAN SAYURAN DI MASYARAKAT PESISIR PULAU MECAN BATAM KEPULAUAN RIAU
}

\section{CULTIVATION AND MANAGEMENT VEGETABLE IN COASTAL COMMUNITIES MECAN ISLAND BATAM KEPULAUAN RIAU}

\author{
Suryo Hartanto ${ }^{1}$, Fenny Agustina ${ }^{2}$, Yustinus Farid Setyobudi ${ }^{3}$ \\ ${ }^{1}$ (Prodi Pendidikan Matematika, Universitas Riau Kepulauan) \\ ${ }^{2}$ (Prodi Pendidikan Biologi Universitas Riau Kepulauan) \\ ${ }_{3}^{3}$ (Prodi Ilmu Pemerintahan Universitas Riau Kepulauan) \\ suryo@fkip.unrika.ac.id
}

\begin{abstract}
Abstrak
Pulau Mecan merupakan salah satu gugusan pulau terluar Indonesia yang terletak di wilayah Kelurahan Sekanak Raya, Kecamatan Belakang Padang, Kota Batam. Sayur mayur sebagai salah satu kebutuhan pokok masyarakat untuk memenuhi kecukupan gizi keluarga sangat susah didapatkan. Wilayah Pulau mecan tidak memungkinkan dilakukan pertanian konvensional untuk sayur mayur karena kondisi tanah bauksit dan wilayah mangrove dan berlumpur disertai dengan banyaknya sampah organik atau anorganik dari masyarakat dan kiriman dari laut sekitarnya. Tujuan dari Program Kemitraan Masyarakat adalah: 1.Budidaya sayuran di masyarakat dengan memanfaatkan sampah dengan metode Hidroponik, 2. Pengelolaan hidroponik melalui nutrisi cair dengan limbah organik, 3.Pengelolaan hasil panen hidroponik dan nutrisi cair untuk peningkatan ekonomi. Budi daya dan pengelolaan sayuran di masyarakat pesisir pulau mecan, Batam, Kepulauan Riau, dilakukan dengan metode penyuluhan dan praktek secara langsung kepada masyarakat untuk melakukan budidaya sayuran dengan metode hidroponik, pengelolaan pupuk cair dan pengelolaan dan pengemasan hasil panen hidroponik serta pupuk cair. Hasil dari kegiatan Program kemitraan masyarakat ini adalah kecukupan kebutuhan sayur mayur di pulau mecan dengan memberdayakan limbah dan sampah yang ada disekitar lingkungan, peningkatan pendapatan masyarakat sebagai hasil sampingan selain hasil laut.
\end{abstract}

Kata Kunci : Budidaya Sayuran, Hidroponik, Pupuk cair

\begin{abstract}
Mecan Island is one of Indonesia's outermost islands located in the Sekanak Raya, District of Belakang Padang, Batam. Vegetables as one of the basic needs of the community to fulfill the adequacy of family nutrition is very difficult to obtain. The area of Mecan Island is not possible to do conventional farming for vegetables because the condition of bauxite and mangrove areas and muddy soil is accompanied by the large amount of organic or anorganic waste from the community and the surrounding sea. The objectives of the Community Partnership Program are: 1. Cultivating vegetables in the community by utilizing waste using the Hydroponic method, 2. Managing hydroponics through liquid nutrition with organic waste, 3. Management of hydroponic and liquid nutrients for economic improvement. Cultivation and management of vegetables in the coastal communities of the island of Mecan, Batam, Kepulauan Riau, was carried out with methods of counseling and practice directly to the community to carry out vegetable cultivation using hydroponic methods, management of liquid fertilizers and management and packaging of hydroponic crops and liquid fertilizers. The result of this community partnership program activity is the adequacy of vegetable needs on Mecan Island by empowering waste and waste around the environment, increasing people's income as a by-product other than marine products.
\end{abstract}

Keywords: Vegetable Cultivation, Hydroponics, liquid fertilizer 


\section{PENDAHULUAN}

Pulau Mecan merupakan salah satu gugusan kepulauan di Kota Batam, Provinsi Kepulauan Riau, tepatnya di Kecamatan Belakang Padang, Kelurahan Sekanak Raya. Jarak antara Pulau Batam sebagai main land dengan Pulau Mecan sekitar 16.35 Km, dengan menggunakan perjalanan laut. Transportasi utama pulau tersebut menggunakan "Pancong" perahu kecil dengan mesin tempel dengan kapasitas 10-30 orang, atau dengan perahu lebih kecil tanpa mesin dengan kapasitas 1-3 orang. Pulan Mecan dihuni oleh sekitar 50 kepala keluarga, dengan mata pencaharian utama sebagai nelayan. Mayoritas penduduk adalah suku melayu dengan agama Islam, (SKPD.Batam. 2017). Pulau mecan hanya terdiri dari satu rukun tetangga yaitu RT.03 yang masuk dalam lingkungan RW .06 Pulau Sarang, Kelurahan Sekanak Raya. Pulau Mecan merupakan salah satu pulau terluar yang berbatasan dengan negara Singapura. Kondisi kepulauan dengan akses transportasi yang tidak tercukupi, serta kondisi lingkungan pantai, menimbulkan banyak kendala dan masalah yang dihadapi oleh masyarakat Pulau Mecan. Berikut adalah foto-foto lingkungan Pulau Mecan.
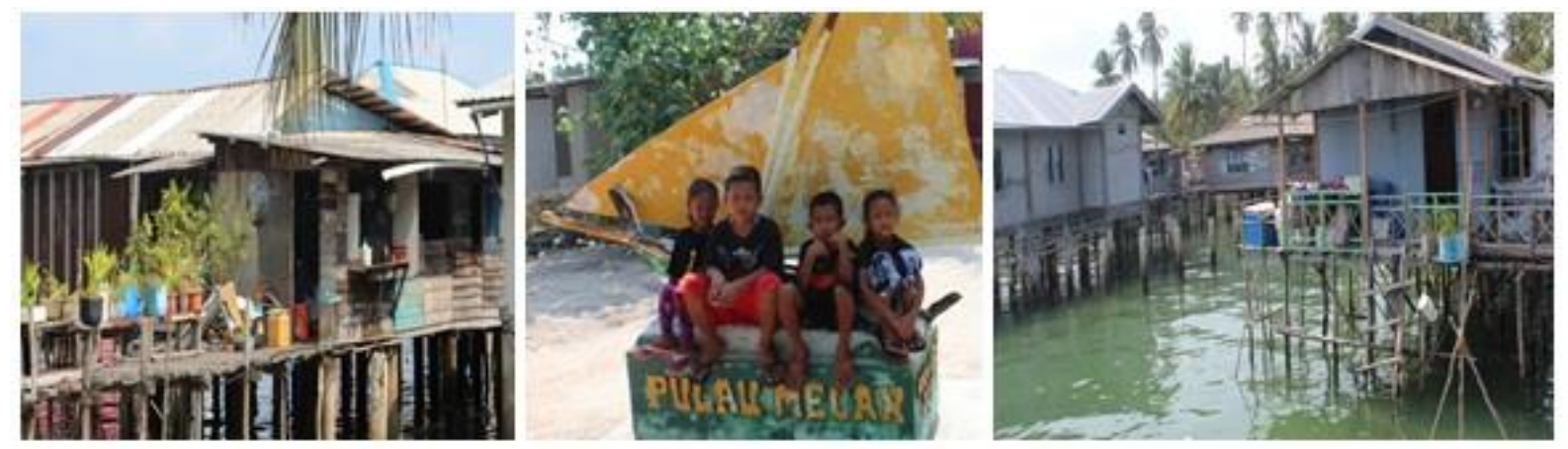

Figur 1. Lingkungan Sekitar Pulau Mecan

Figur 1, menunjukkan kondisi lingkungan perumahan di pulau mecan, yang sebagian besar adalah rumah panggung diatas pantai, sedangkan pada gambar 2, memperlihatkan kondisi tanah pada sekitar pulua serta berkurangnya lahan magrove yang dijadikan pemukiman tepi laut. Figur 2. Menunjukkan kegiatan harian yang dilakukan oleh penduduk pulau Mecan, apabila tidak melaut karena musim yang tidak cocok. Perbaikan jaring dan pembuatan bubu (perangkap ikan) dilakukan sebagai usaha sampingan. Bubu pada masyarakat pulau mecan dijadikan alat tangkap kepiting, yang dipasang pada beberapa tempat, ditinggalkan dan pada beberapa hari kedepan 
akan diambil kembali. Kondisi keluarga terutama ibu-ibu, sebagaian besar hanya mengurus anak dan keluarga.
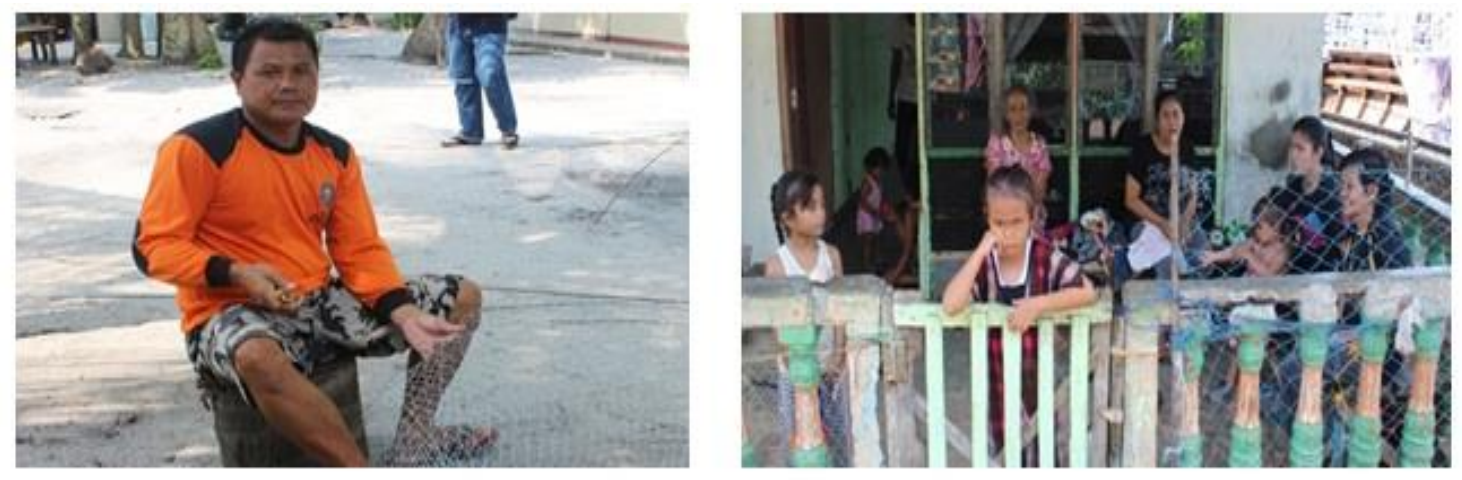

Figur 2. Kehidupan Nelayan Pulau mecan

Pulau mecan sebagai salah satu gugusan pulau kecil, telah memiliki karakteristik khusus yang berbeda dengan daerah lain. Hal ini sesuai dengan yang disampaikan oleh Bengen et al (2002), pulau kecil memiliki karakteristik biogeofisik yang menonjol, yaitu: 1).Terpisah dari habitat pulau induk (mainland island), sehingga bersifat insular, 2). Sumberdaya air tawar yang terbatas, dimana daerah tangkapan airnya relatif kecil, 3). Peka dan rentan terhadap pengaruh eksternal baik alami maupun akibat kegiatan manusia, misalnya badai dan gelombang besar, serta pencemaran, 4). Memiliki sejumlah jenis endemik yang bernilai ekologis tinggi, 5). Area perairan yang lebih luas dari area daratannya dan relatif terisolasi dari daratan utamanya (benua atau pulau besar), 6). Tidak mempunyai hinterland yang jauh dari pantai. Karakteristik kepulauan harus menjadi rujukan khusus untuk melakukan pengembangan dan perbaikan lingkungan sosial, ekonomi masayarakat pada pulau Mecan. Potensi yang dimiliki harus menjadi salah satu solusi untuk memecahkan masalah yang terjadi di pulua tersebut.

Berdasarkan survei kondisi di Pulau Mecan, dilakukan identifikasi berbagai permasalahan yang ada, berdasarkan identifikasi maka dilakukan langkah-langkah pemecahan masalah untuk masyarakat Pulau Mecan di RT.03/RW.06 kel. Sekanak raya, yang dianggap sangat mendesak untuk dilakukan.

Lingkungan pulau dengan dikelilingi oleh pantai lautan, dengan kontur tanah berpasir dan lumpur, serta alat transportasi yang minim, menimbulkan dampak yang berkepanjangan terhadap pemenuhan kebutuhan bahan makanan pokok. Salah satu kebutuhan makanan adalah sayur 
mayur. Sayur-sayuran merupakan komoditas yang sangat dibutuhkan oleh semua kalangan masyarakat untuk menjamin kelangsungan hidup sehat, bahkan untuk wilayah kepulauan terpencil yang minim lahan pertanian. Dengan kondisi lingkungan yang telah disebutkan diatas maka sangat tidak mungkin dilakukan pertanian konvensional untuk memenuhi kebutuhan sayur mayur secara mandiri di Pulau Mecan.

Pertanian sayur mayur membutuhkan dukungan unsur hara yang tepat untuk mencapai pertumbuhan yang baik dan maksimal. Penduduk Pulau Mecan meyebutkan harga beli sayur, misalnya sawi, kangkung pada kisaran Rp.10.000/kg, bayam Rp.12.000/kg, sedangkan komoditi selain sayuran, semisal cabai, harganya akan lebih tinggi, (Batam Pos. 2016, Desperindag Batam, 2016). Harga pada dasarnya tidak jauh berbeda dengan pulau sekitarnya namun transportasi yang mahal menimbulkan upaya untuk mendapatkan sayuran untuk konsumsi menjadi sangat mahal dan tidak terjangkau. Masyarakat Pulau Mecan memenuhi kebutuhan sayuran dengan membeli sayuran tersebut di pulau sekitarnya yaitu Pulau Belakang Padang atau Pulau Pemping. Jarak antar pulau tersebut sekitar 30 menit menggunakan perjalanan laut dengan transportasi pompong. Hal ini akan menjadi lebih mahal lagi, mengingat $85 \%$ kebutuhan sayuran Kota Batam dan sekitar, disuplai dari luar daerah Batam, (Rudi. 2016).

Lingkungan pantai yang menjadi tempat tinggal warga terkesan kumuh dengan banyaknya sampah, botol plastik, plastik kantong, limbah pengelolaan ikan yang dibuang sembarangan dan sampah kiriman dari laut yang tidak bisa diprediksi kedatangannya. Tempat tinggal yang berada diatas pantai dengan tipikal rumah panggung semakin mempersempit pengelolaan lingkungan, terutama dibawah rumah pangung tersebut. Tiang pancang rumah panggung menjadi salah satu sarana berkumpulnya sampah akibat tersangkut pada tiang tersebut. Rendahnya kesadaran masyarakat terhadap kondisi lingkungan semakin memperparah tingkat kesehatan lingkungan di Pulau Mecan.

Perekonomian masyarakat pulau yang kebanyakan nelayan, tidak memiliki usaha sampingan yang dapat digunakan untuk menambah kecukupan hidup. Apabila musim angin atau cuaca tidak memungkinkan untuk melaut maka kecenderungan yang terjadi adalah menganggur atau memperbaiki alat tangkap ikan. Tualng punggung keluarga adalah suami, sedangkan ibu-ibu di Pulau Mecan hanya sebagai ibu rumah tangga. Melalui Program Kemitraan Masyarakat 
dilakukan beberapa solusi tindakan untuk menyelesaikan masalah yang terjadi pada Pulau Mecan. Masalah yang telah disampikan menjadi sangat penting untuk diselesaikan karena menyangkut kelayakan hidup dan kesejahteraan masyarakat di Pulau Mecan. Tujuan dari kegiatan Program Kemitraan Masyarakat di Pulau Mecan ini adalah: 1). Memenuhi kebutuhan sayuran untuk rumah tangga dengan system tanam pengelolaan sampah secara mandiri. 2). Memeberdayakan sampah sebagai penunjang tanaman sayuran di Pulau Mecan, 3). Peningkatan pendapatan ekonomi masyarakat dari pengelolaan sampah di Pulau Mecan.

\section{METODOLOGI}

Metode Pelaksanaan PKM dibagai menjadi 3 tahapan, untuk memecahkan masalah yang dihadapi pada masyarakat Pulau mecan. Tahapan yang dilakukan adalah solusi permasalaahan berupa pelatihan dan monitoring kegiatan yang dilakukan secara bertahap. Keterlibatan mitra sangat penting mengingat hal ini menyangkut penyelesaian kendala yang ada di Pulau Mecan. Keterlibatan masyarakat secara aktif dapat dilakukan dengan melibatkan tokoh masyarakat dan pengelola RT dilingkungan Pulau Mecan. Dalam kegiatan PKM ini juga melibatkan mahasiswa untuk berperan dalam pelaksanaan 3 solusi yang telah ditawarkan yang dijabarkan pada gambar berikut:

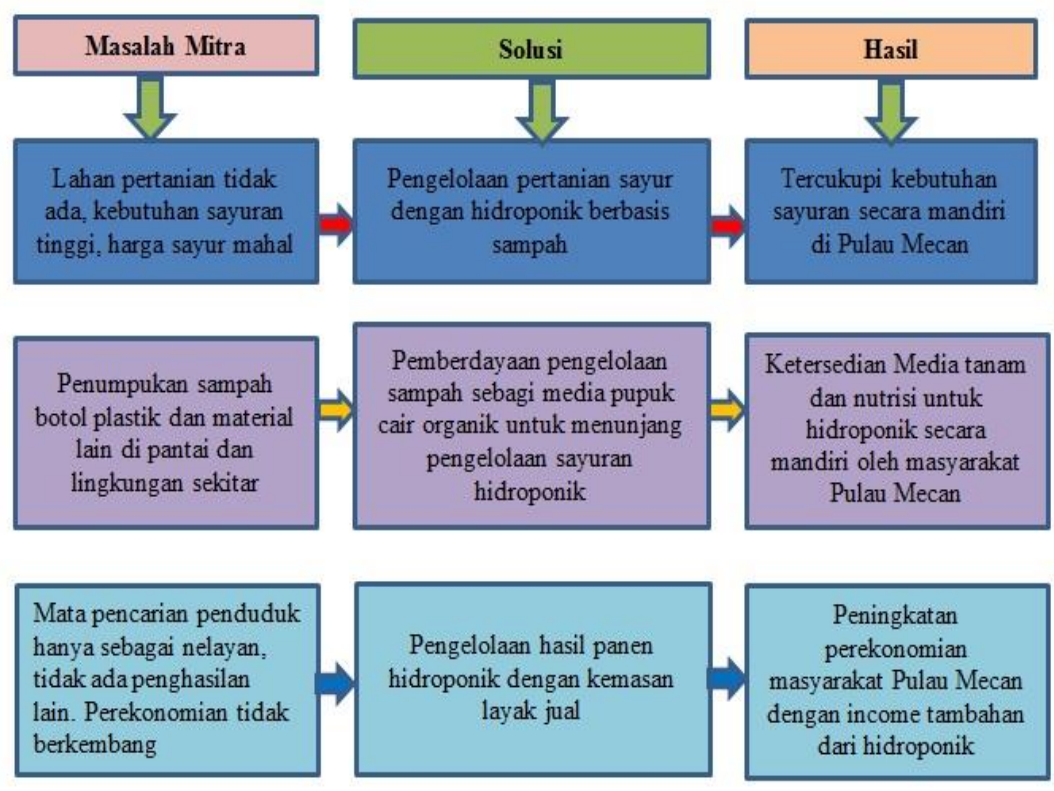

Figur 3. Metode Pelaksanaan PKM 


\section{HASIL DAN PEMBAHASAN}

Berdasarkan tujuan dan metodologi kegiatan yang dilaksanakan dalam PKM ini, didapatkan tiga penjabaran sebagai berikut:

\section{Pengelolaan bertanam sayur dengan hidroponik berbasis sampah.}

Pengelolaan ini dapat diwujudkan dengan work shop atau pelatihan. Kegiatan ini dilakukan dengan cara presentasi dan praktek langsung cara bertanam sayuran dengan hidroponik kepada masyarakat di Pulau Mecan. Sistem hidroponik yang digunakan adalah sistem Wick, dengan memanfaatkan sampah-sampah yang berada dilingkungan sekitar Pulau Mecan, antara lain, botol plastik ukuran 1liter, sabut kelapa, kain bekas, dan kardus bekas telur. Masyarakat diajak secara langsung untuk andil dalam kegiatan ini, sehingga menghasilkan tanaman sayuran hidroponik. Persiapan yang dilakukan adalah penyediaan alat-alat pendukung antara lain. Cutter/gunting, solder, botol bekas, kain bekas, kardus tempat telur bekas, sabut kelapa yang sudah dihancurkan menjadi serpihan kecil, isolasi/lakban, bibit sayuran (kangkung, sawi, bayam, cabe, letuce),Pupuk cair. (Infoaquakultur, 2016).

Wick System, Wick hidroponik atau system sumbu adalah metode hidroponik paling sederhana karena hanya memanfaatkan prinsip kapilaritas, (Heru. 2014, Info Agribisnis, 2017). Larutan nutrisi dari bak penampungan menuju perakaran tanaman pada posisi di atas dengan perantaraan sumbu, mirip cara kerja kompor minyak.

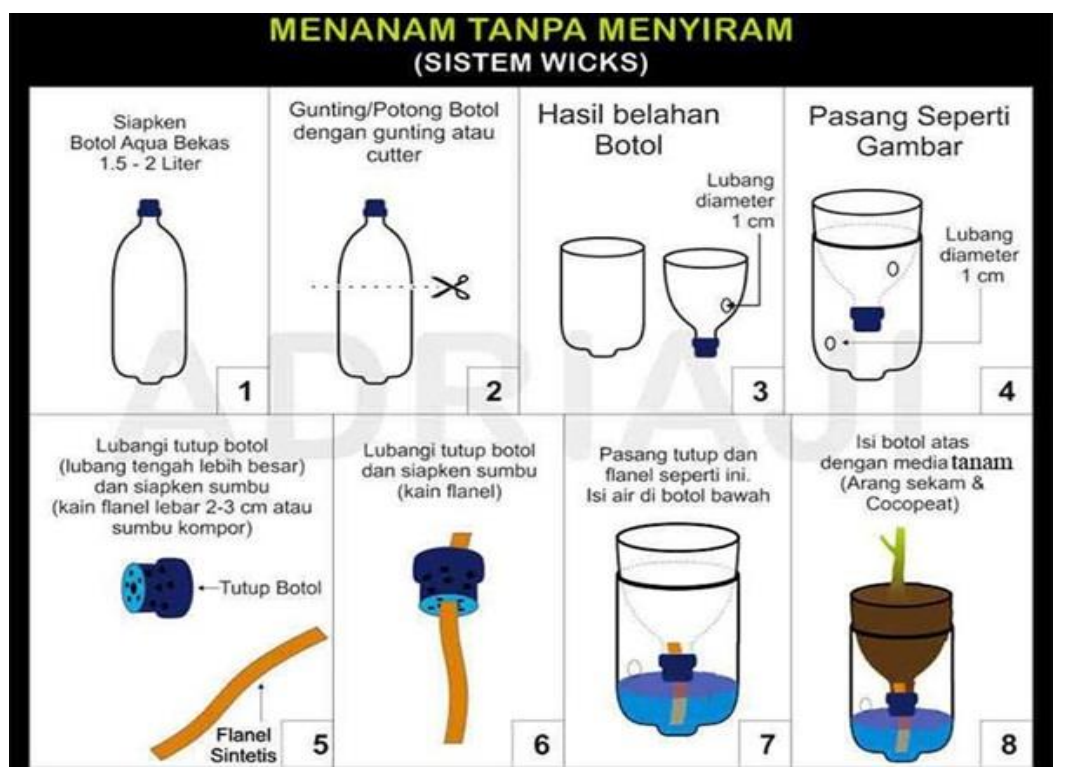


Figur 4. Skema WickSystem.

Masyarakat Pulau Mecan sangat antusias dengan kegiatan pelatihan ini, mengingat ilmu dan pengetahuan yang didapatkan sangat mudah dipelajari dan memberikan keuntungan yang baik bagi keluarga dan lingkungan masyarakat sekitar.
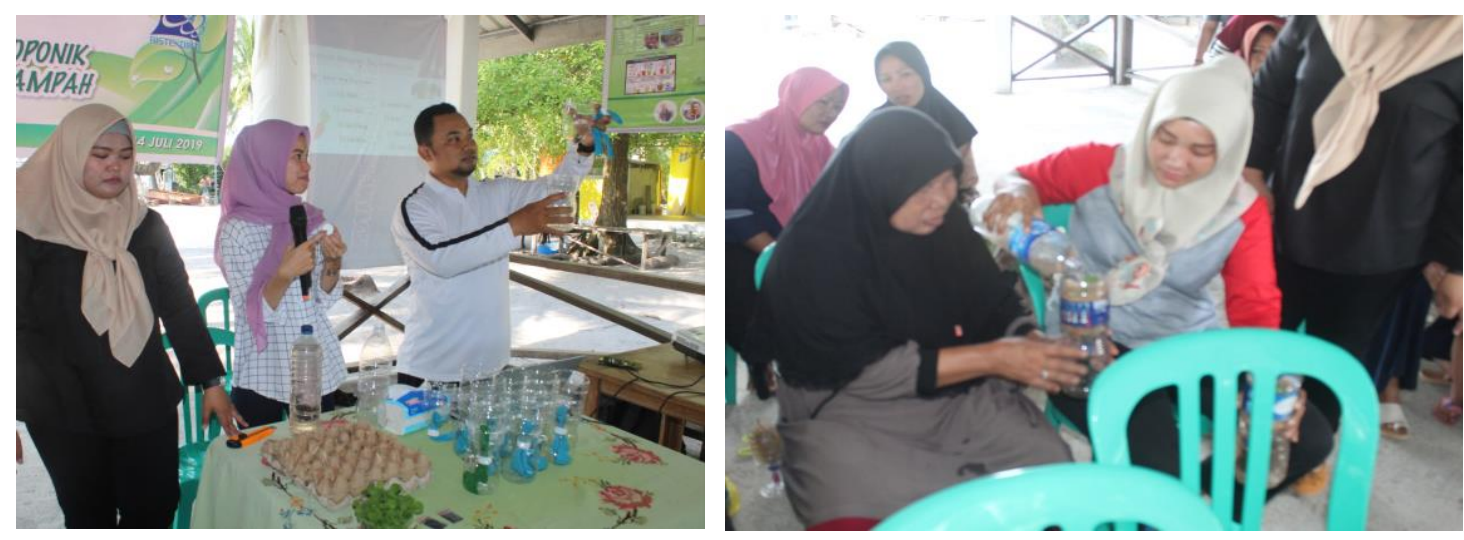

Figur 5. Kegiatan pelatihan hidroponik berbasis sampah

\section{Pemberdayaan pengelolaan sampah pupuk cair organik untuk menunjang pengelolaan sayuran hidroponik.}

Pemberdayaan pengelolaan dilakukan dalam bentuk pelatihan atau work shop kepada masyarakat Pulau Mecan. Kegiatan ini dilakukan selanjutnya sesuai dengan jadwal kegiatan PKM, dengan pembuatan pupuk cair organik dengan memanfaatkan limbah/sampah yang ada dilingkungan sekitar Pulau Mecan. Pelatihan ini untuk menunjang keberlanjutan sistem tanam hidroponik yang sudah berjalan sebelumnya. Sistem tanam sayuran dengan hidroponik memerlukan nutrisi atau unsur-unsur yang diperlukan untuk dapat tumbuh subur dan sehat. Unsur yang dibutuhkan oleh tumbuhan terdiri dari unsur makro dan mikro. Unsur hara makro terdiri dari makro primer seperti $\mathrm{N}, \mathrm{P}$, dan $\mathrm{K}$; makro sekunder seperti $\mathrm{Ca}, \mathrm{Mg}$, dan $\mathrm{S}$; sedangkan unsur hara mikro terdiri dari $\mathrm{Fe}, \mathrm{Zn}, \mathrm{Cu}, \mathrm{Mn}, \mathrm{Cl}$, Bo, Mo,(Organic Hcs, 2018, Akuakultur, 2016).

Kecukupan nutrisi ini dapat dipenuhi salah satunya dengan mengolah lombah rumah tangga/sampah organik sisa jeroan ikan atau hasil laut lainnya. Pengelolaan dilakukan secara sistematis sehingga menghasilkan pupuk cair organik berkualitas yang siap digunakan untuk budidaya sayuran hidroponik. Persiapan yang dilakukan antara lain: limbah organik rumah tangga, contoh jeroan ikan/hasil laut. Alat perebusan, media fermentasi. 

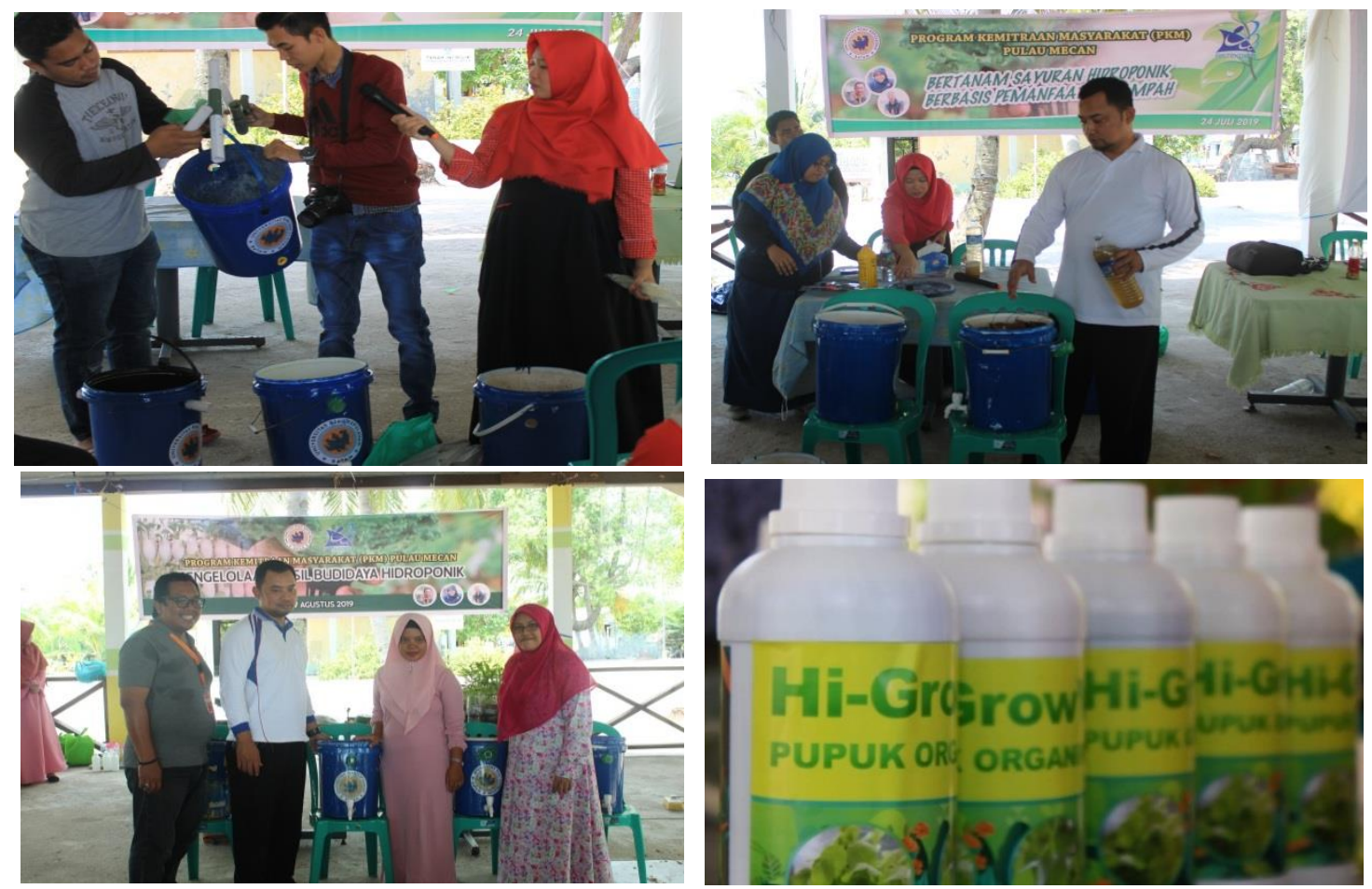

Figur 6. Pelatihan pengolahan pupuk organic cair

\section{Pengelolaan hasil panen hidroponik}

Hasil budidaya sayuran dengan sistem hidroponik menjanjikan keberhasilan sampai dengan 90\%. Maka hasil budidaya akan sangat berlimpah untuk pemenuhan kebutuhan rumah tangga saja. Di perlukan pemberdayaan hasil panen dengan pengelolaan agar sayuran tersebut dapat dijual sehingga menambah masukan untuk ekonomi rumah tangga.

Program pengelolaan dilakukan dalam bentuk work shop atau pelatihan. Beberapa hal yang perlu disiapkan adalah: plastik kemasan, label kemasan, mesin pemanas plastik, sayuran segar yang siap kemas. Pengemasan memberikan manfaat pengawetan dan meningkatkan daya jual (Badru. 2009). Pelatihan dilakukan sebagai upaya edukasi masyarakat di Pulau Mecan untuk mendapatkan penghasilan tambahan dari hasil hidroponik.

Berdasarkan hasil kegiatan yang dirangkai dalam program kemitraan masyarakat, beberapa masalah yang terjadi di Pulau Mecan dapat teratasi. Kendala yang terdapat dalam masyarakat dapat teratasi dengan memanfaatkan sumber daya yang tersedia di pulau tersebut. Melalui system tanam dengan hidroponik dan pengelolaan sumber nutrisi hidroponik dengan bahan organic. 

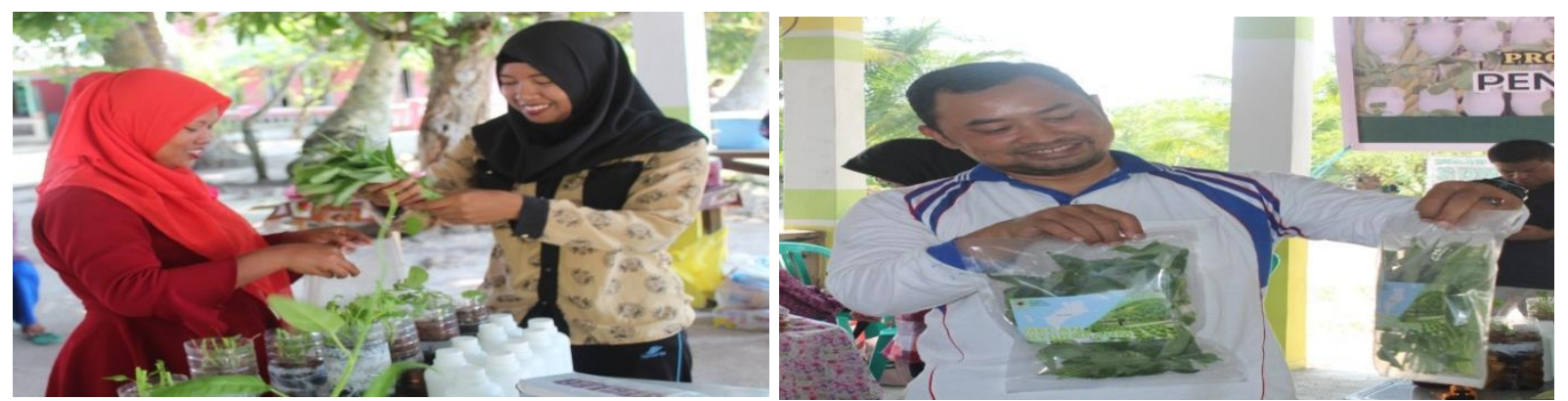

Figur 7. Pengelolaan hasil pertanian hidroponik

\section{KESIMPULAN DAN SARAN}

Beradasarkan hasil kegiatan PKM yang telah dilakukan maka dapat disimpulkan bahwa: 1). Kebutuhan sayuran dipulau mecan dapat teratasi dengan budidaya sayuran menggunakan system hidroponik, 2). Pemberdayaan sampah dilingkungan sekitar Pulau mecan diatasi dengan hidroponik berbasis sampah dan pengelolaan sampah organic menjadi pupuk cair. 3). Peningkatan pendapatan masyarakat Pulau Mecan dengan pengelolaan hasil tanam hidroponik dan pupuk organic cair dengan kemaasan yang bernilai jual.

\section{REFERENSI}

Aquakultur. (2016). Raup untung dari pupuk organik berbahan limbah ikan. Versi elektronik diakses dari: http://infoakuakultur.com.

Badru Setiawan. 2009. Proses Dan Cara Pengemasan Sayur-Sayuran. Diakses dari http://badrussetiawan1.blogspot.com/2009/04/proses-dan-cara-pengemasan-sayur.html

Batam Pos. (2016). Harga Cabai Merah Meroket Hingga Rp68 Ribu Perkilogram. Diakses dari: http://batampos.co.id

Bengen, D. G., A. Tahir, A. Rizal dan Pawitno. 2002. Pengembangan Konsep Daya Dukung dalam Pengelolaan Lingkungan Pulau-pulau Kecil. Laporan Akhir. Kerjasama Kementerian Lingkungan Hidup (KLH) dengan Fakultas Perikanan dan Ilmu Kelautan Institut Pertanian Bogor. Jakarta: KLH.

Desperindag Batam. (2018). Daftar Harga Komoditi tanggal 16 Agustus. Diakses darhttps://disperindag.batam.go.id/2018/08/16/daftar-harga-komoditi...pada Agustus 2018.

Heru Agus Hendra dan Agus Andoko. (2014). Bertanam Sayuran Hidroponik ala Paktani Hydrofarm. Jakarta: PT. Agromedia Pustaka.

Info Agribisnis (2017). Cara Bertanam Hidroponik. Diakses dari: http://www.infoagribisnis.com/2017/04/cara-bertanam-hidroponik/, pada Agustus 2018. 
Info Akua Kultur. 2016. Raup Untung dari Pupuk Organik Berbahan Limbah Ikan diakses dari: http://infoakuakultur.com/blog/raup-untung-dari-pupuk-organik.. Pada Agustus 2018.

Organic Hcs.(2018). Unsur Hara Makro dan Mikro yang dibutuhkan oleh Tanaman. Diakses dari: https://organichcs.com/2014/05/03/unsur-makro-dan-mikro-yang-dibutuhkan... Pada Agustus 2018.

Rudi Syatyakirti (2016). 85 Persen sembako di Batam berasal dari Luar Daerah, diakses dari: http://www.tribunnews.com

SKPD Kota Batam. (2017). Profil Kecamatan Belakang Padang. Diakses dari: https://arsipskpd.batam.go.id/batamkota/skpd.batamkota.go.id/belakangpadang/profil...pada Agustus 2018. 